\title{
Predictors of Time to First Line Antiretroviral Treatment Failure among Adult Patients Living with HIV in Public Health Facilities of Arba Minch Town, Southern Ethiopia
}

\author{
Bilcha Oumer Enderis ${ }^{1}$, Sultan Hussen Hebo ${ }^{2 *}$, Mesfin Kote Debir ${ }^{2}$, Negussie \\ Boti Sidamo $^{2}$, Mulugeta Shegaze Shimber ${ }^{2}$
}

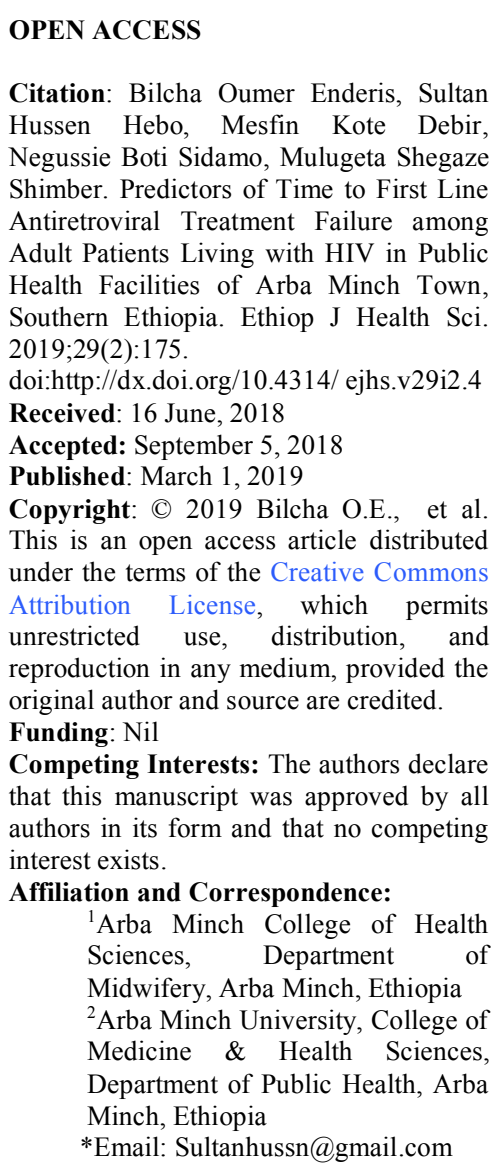

\begin{abstract}
BACKGROUND: Antiretroviral therapy is a proven medication given for Human Immunodeficiency Virus positive individuals. However, first-line antiretroviral treatment failure becomes a public health issue and early detection of treatment failure is crucial for timely actions. Therefore, this study aimed to identify the predictors of time to first-line antiretroviral treatment failure among adult patients living with HIV in public health facilities of Arba Minch Town.

METHODS: Institution-based retrospective cohort study was employed among 396 adult patients that were selected using simple random sampling. The data on relevant variables were extracted from patient medical cards. Bi-variable and multi-variable Cox proportional hazard regression analyses were used to identify predictors.

RESULTS: The median survival time was 21 months. Substance use $(A H R=2.94,95 \% C I=1.62$ to 5.32), disclosure status $(A H R=1.98,95 \% C I=1.03$ to 3.79$)$, time since $H I V$ diagnosis $(A H R=2.1995 \% \quad C I=1.01$ to 4.79), WHO clinical stage (AHR=2.02, 95\% CI=1.02 to 4.00), opportunistic infection $(A H R=2.27,95 \% C I=1.23$ to 4.19$)$, nutritional status $(A H R=3.78$, 95\% CI=1.99 to 7.17), functional status $(A H R=2.7195 \% C I=1.33$ to 5.51), CD4 count $(A H R=1.99,95 \% C I=1.05$ to 3.75), and adherence level $(A H R=1.99,95 \% C I=1.05$ to 3.76$)$ were independent predictors of time to first line ART treatment failure. CONCLUSION: History of substance use, lack of disclosure status, time since HIV diagnosis, advanced WHO clinical staging, low CD4 counts, opportunistic infection, functional status, poor adherence to $A R T$ and under-nutrition affect the time to first-line treatment failure among adult patients living with HIV. Therefore, preventive interventions, and information and counseling focusing on high risk groups of HIV infected adult are very important.

KEYWORDS: Time to first line treatment failure, Poor adherence, Under-nutrition, Arba Minch
\end{abstract}




\section{INTRODUCTION}

Human Immunodeficiency Virus (HIV) infection continues to be one of the public health issues $(1,2)$. Worldwide, approximately 36.7 million people were living with HIV/AIDS at the end of 2016 (3). Sub-Saharan Africa is the most affected region, with nearly 1 in every 25 adults living with HIV (3). In Ethiopia, a total of 718,500 people were living with HIV/AIDS at the end of 2016, and adult HIV prevalence was estimated $1.1 \%(4,5)$.

To tackle this problem, new global efforts brought that the number of people receiving HIV treatment increased dramatically in recent years, particularly in resource-poor countries (3). Among resource-poor countries, Ethiopia has achieved a significant success in scaling up antiretroviral therapy (ART) services since 2005 (5).

Effective ART is usually convoyed by an increase in the number of CD4+ T - cells and the functional restoration of patents' immune responses and decline in HIV viral load. However, the requirement of regular and lifelong medication of HIV patients is challenged with emergencies of treatment failure $(2,5)$.

First line ART failure enhances drug toxicity and drug resistance which are associated with high risk to transmission of drug resistant virus, increase in treatment complexity, worsening morbidity and mortality in HIV/AIDS adults. In addition, $46 \%$ of HIV infected patients with first line ART failure have higher probability to fail again for second-line drug and ultimately, failure of the HIV treatment program $(6-8)$.

Studies assessing immunological failure from ART initiation to occurrence of immunological failure found that median duration of treatment failure was 36 month (9). Moreover, another finding which assessed virologic failure from ART initiation to occurrence of virologic failure found that median survival time was 25.9 months to 37 months $(10,11)$.

To clearly understand how these time to treatment failures vary and to offer rigorous care for those at risk of treatment failure, understanding the factors that are associated with time to first line treatment failure is very crucial.
Furthermore, it will improve the antiretroviral drug resistance and increase durability of first line ART treatment $(7,12)$.

There have been different studies that tried to reveal different factors associated with time to first line treatment failure among adult ART users. For instance, WHO clinical stage $(13,14)$, CD4 count $(6,7,15)$, co-infection with tuberculosis $(8,16,17)$, sex of clients $(14,15,18)$ and adherence to therapy $(10,16,17)$ are the major predictors of time to first line ART failure. However, as far as our search engine was concerned, variables like baseline regimen, body weight, lack of disclosure of HIV status to the family members, time since HIV diagnosis and history of substance use were not well explored. Therefore, this study aimed to identify predictors of time to first line antiretroviral treatment failure among adult people living with HIV in public health facilities of Arba Minch Town by incorporating these very important variables.

\section{MATERIALS AND METHODS}

Study setting, design and participants: An institutional-based retrospective cohort study was conducted from February to March, 2018, among adults enrolled on first line ART between January 01, 2013 and December 30, 2017 in Public Health Facilities of Arba Minch Town. The study included patients (aged $\geq 15$ years) who had follow-up for at least 6 months after starting first line antiretroviral treatment. Pregnant women, patients who started ART at another site and incomplete recording of baseline data for the study were excluded.

Sample size determination and sampling technique: The required sample size for this study was calculated based on double population proportion formula. TB co-infection at ART initiation was used as the most significant predictor of time to first line ART failure from the study by Haile at Bale Zone Hospitals and the following assumptions were considered (16). The proportion of patients with TB co-infection at ART initiation among adult who failed first line ART (exposed group) was $12.1 \%$ and proportion of patients without TB co-infection at ART

DOI: http://dx.doi.org/10.4314/ejhs.v29i2.4 
initiation among adult who failed first line ART (non-exposed group) was 3.95\%; and 95\% CI, power of $80 \%$, AHR of 3.06, ratio of one to one were used. Using Epi-Info-7.2 StatCalc the calculated sample size was 396.

Simple random sampling technique was used to select study participants. From one hospital and one health center of Arba Minch Town, adult HIV patients on ART for $\geq 6$ months and enrolled between January 01, 2013 and December 30, 2017, were selected. Then, each adult on first line ART in selected health facilities with complete recording of baseline data for the study was identified, and corresponding card identification number was given to develop sampling frame. Then, study subjects were proportionally allocated to each selected health facility. Then the tudy participant were selected using simple random sampling techniques.

Data collection procedures and measurements: The standard data extraction tool was prepared in English language for recording information from patients' cards. This form was developed using the revised 2017 Federal Ministry of Health patient card, ART intake forms, HIV care followup and further modified by using different peer reviewed published literatures $(7,12,16,19)$.

Treatment failure was measured either by clinical failure (which occurred when there was a new or recurrent WHO stage 3 or 4 condition) or immunological failure (occurred when CD4 count fell from baseline (below) or 50\% fall of absolute CD4 count from the on-treatment peak value or persistent CD4 levels below 100 cells $/ \mathrm{mm}^{3}$ ) or virological failure (occurred when plasma VL $>$ $1000 \mathrm{copied} / \mathrm{ml})(20)$.

The time to treatment failure after starting first line ART was calculated in months using the time between dates of treatment initiation to date of event (treatment failure) or date of censored.The starting point for this study was from initiation of ART between January 01, 2013 to December 30, 2017 and the endpoint was either treatment failure, death, loss to follow-up, transfer to another health institution and alive up to end of the study without developing treatment failure.

Data were collected by 6 health professionals and supervised by 2 health professionals who were trained in comprehensive HIV care to ensure the quality of data. The data were collected by reviewing the patients' medical cards. The missed data from patients' medical records were cross checked with ART electronic database. The most recent laboratory results before starting ART were used as a base line value.

Data processing and analysis: After data collection, each questionnaire was checked for completeness and consistency. Data were cleaned, edited, coded and entered into EPI-Data version 3.1 and exported to STATA version 11 for analysis. Descriptive statistical metods like median, inter-quartile rage, mean, standard deviation and proportions were used to describe socio-demographic, baseline clinical related and follow-up characteristics of cohorts. Kaplan Meier survival curve was used to describe time to treatment failure from initiation of antiretroviral therapy. Both bi-variable and multi-variable Cox proportional hazard regression models were used to assess independent predictors of time to first line ART treatment failure. Variables with $\mathrm{p}$ value $\leq 0.25$ in the bivariable Cox proportional hazards model were entered into the multivariable Cox proportional hazards model analysis to identify independent predictors of time to first line treatment failure.

A p-value less than 0.05 was used to include a variable in the final model. The crude and adjusted hazard ratios together with their corresponding $95 \%$ confidence intervals were computed and interpreted accordingly.

Data quality assurance: To assure the quality of data, different mechanisms were used including pre-testing of the data extraction checklist on 5\% sample size, careful design of data extraction formats, using appropriate recruitment of data collectors and giving adequate training and follow-up for data collectors and supervisors.

Ethical statement: Ethical clearance was obtained from the IRB of Arba Minch University, College of Medicine and Health Sciences. Personal identifiers were excluded during data extraction; codes were used instead. Because the study was being conducted on secondary data, obtaining informed consents from the participants was not possible.

DOI: http://dx.doi.org/10.4314/ejhs.v29i2.4 


\section{RESULTS}

Socio-demographic characteristics: A total of 396 adult patients receiving ART treatment from December 2013 to January 2017 were enrolled in the study. Of these, 297(75\%) were from hospital and $99(25 \%)$ were from health center. Two hundred and three $(51.3 \%)$ participants were followed ART treatment for more than 12 months (Table 1).

Table 1: Baseline socio demographic characteristics of adult enrolled on first line ART at Public Health facilities of Arba Minch Town, Gamo Gofa Zone, Southern, Ethiopia, 2018

\begin{tabular}{|c|c|c|}
\hline Variables & Frequency (n) & Percent (\%) \\
\hline \multicolumn{3}{|c|}{ Type of Health facilities } \\
\hline Hospital & 297 & 75 \\
\hline Health center & 99 & 25 \\
\hline \multicolumn{3}{|l|}{ Age (Year) } \\
\hline $15-24$ & 53 & 13.4 \\
\hline $25-34$ & 181 & 45.7 \\
\hline $35-44$ & 112 & 28.3 \\
\hline $45+$ & 50 & 12.6 \\
\hline \multicolumn{3}{|l|}{ Sex } \\
\hline Male & 187 & 47.28 \\
\hline Female & 209 & 52.78 \\
\hline \multicolumn{3}{|l|}{ Marital status } \\
\hline Never Married & 121 & 30.6 \\
\hline Married & 215 & 54.3 \\
\hline Divorced & 40 & 10.1 \\
\hline Widowed & 20 & 5 \\
\hline \multicolumn{3}{|l|}{ Educational status } \\
\hline No education & 45 & 11.4 \\
\hline Primary & 139 & 35.1 \\
\hline Secondary & 173 & 43.7 \\
\hline Tertiary & 39 & 9.8 \\
\hline \multicolumn{3}{|l|}{ Religion } \\
\hline Orthodox & 240 & 60.6 \\
\hline Muslim & 11 & 2.8 \\
\hline Protestant & 112 & 29 \\
\hline Catholic & 26 & 6.6 \\
\hline Others* & 4 & 1.0 \\
\hline \multicolumn{3}{|l|}{ Residence } \\
\hline Urban & 307 & 77.5 \\
\hline Rural & 89 & 22.5 \\
\hline \multicolumn{3}{|l|}{ Ethnicity } \\
\hline Gamo & 157 & 39.7 \\
\hline Gofa & 73 & 18.4 \\
\hline Wolayita & 70 & 17.7 \\
\hline Amhara & 55 & 13.9 \\
\hline Oromo & 28 & 7.1 \\
\hline Others** & 13 & 3.3 \\
\hline
\end{tabular}

DOI: http://dx.doi.org/10.4314/ejhs.v29i2.4 
Table 1 Continued.....

Occupational status

House wife 95

Private employee $\quad 54$

Merchant

101

23.9

Government employee

65

13.6

Student

48

25.5

Farmer

33

16.4

Substance use

Yes

No

Disclosure status

Disclosed

163

37.6

Not disclosed

233

41.2

Time since HIV diagnosis

(Years)

$\leq 3$ Years

290

73.2

$>3$ Years

106

26.8

Duration on ART (months)

$<12$

193

48.7

$\geq 12$

203

51.3

*Adventist, Gova** Konso, Gurage,Slite, Tigre

Baseline clinical characteristics: At baseline, $146(36.9 \%)$ of the participants were found on WHO stage I. Almost half of the study participants, 203(51.3\%), had initial CD4 count $\geq 200$ cells $/ \mathrm{mm}^{3}$. The median baseline of CD4 counts was 192.5 cell $/ \mathrm{mm}^{3}$ with inter-quartile ranges of 93.5, 317.5. About three hundred and forty-five $(77.0 \%)$ were working in their functional status at the time of enrollment. Of the study participants, 98(24.8\%) had history of opportunistic infections while $27(27.6 \%)$ of them had TB co-infection at initiation of ART.

Baseline chemoprophylaxis characteristics: About two hundred forty-one (60.9\%) took Cotrimoxazole preventive therapy (CPT) while two and hundred sixty-four $(66.7 \%)$ were taking Isoniazid preventive therapy (ITP) at the time of enrollment. The majority $(68.2 \%)$ of the study participants had good drug adherence followed by fair adherence $(17.2 \%)$. Of the participants, $343(86.6 \%)$ had no drug substitution, but sixty- nine $(17.4 \%)$ failed their initial regimen. The immunologic, clinical and virologic failures were $28(40.6 \%), 14(20.3 \%)$ and $5(7.25 \%)$ respectively. There were $6(8.69 \%)$ participants with both virological and immunological failures and $7(10.14 \%)$ participants with immunological and clinical failures. The number of participants who failed both virologically and clinically was 6 $(8.69 \%)$ while $3(4.35 \%)$ participants were failed clinically, immunologically and virologically.

Time to first line antiretroviral treatment failure: The study participants had a median follow-up period of 10 months (IQR: $7.00-$ 26.75). At the end of follow-up, 69(17.42\%) developed the event (first line antiretroviral treatment failure), and 327(82.58\%) patients were censored observations. The overall median survival time (the expected time to event) was 21 months with $95 \%$ CI $(18,24)$ (Table 2).

DOI: http://dx.doi.org/10.4314/ejhs.v29i2.4 
Table 2: Medians survival times for groups of different variables among adult on first line ART in public health facilities of Arba-Minch Town, Gamo Gofa Zone, Southern, Ethiopia, 2018.

\begin{tabular}{|c|c|c|c|c|}
\hline \multirow{2}{*}{ Variables } & \multirow{2}{*}{$\begin{array}{c}\text { Median } \\
\text { survival time }\end{array}$} & \multirow{2}{*}{$\begin{array}{l}\text { Std. Error of } \\
\text { the Median }\end{array}$} & \multicolumn{2}{|c|}{ 95\% CI of the Median } \\
\hline & & & \multicolumn{2}{|c|}{ Lower bound Upper bound } \\
\hline \multicolumn{5}{|l|}{ Type of health facilities } \\
\hline Hospital & 19 & 1.39 & 16 & 24 \\
\hline Health center & 23 & 1.12 & 12 & 39 \\
\hline \multicolumn{5}{|l|}{ Sex } \\
\hline Male & 21 & 1.89 & 18 & 30 \\
\hline Female & 18 & 1.98 & 12 & 26 \\
\hline \multicolumn{5}{|l|}{ Residence } \\
\hline Urban & 20 & 1.89 & 16 & 24 \\
\hline Rural & 21 & 1.65 & 15 & 37 \\
\hline \multicolumn{5}{|l|}{ Disclosure status } \\
\hline Disclosed & 24 & 1.40 & 18 & 30 \\
\hline Not disclosed & 18 & 1.32 & 15 & 24 \\
\hline \multicolumn{5}{|l|}{ Substance use } \\
\hline Yes & 18 & 1.53 & 12 & 27 \\
\hline No & 23 & 1.85 & 18 & 31 \\
\hline \multicolumn{5}{|l|}{ Time since HIV diagnosis } \\
\hline$\leq 3$ Years & 18 & 1.03 & 14 & 23 \\
\hline$>3$ Years & 24 & 3.29 & 19 & 42 \\
\hline \multicolumn{5}{|l|}{ Duration on ART (months) } \\
\hline$<12$ & 9 & 0.28 & 7 & 11 \\
\hline$\geq 12$ & 24 & 2.41 & 20 & 31 \\
\hline \multicolumn{5}{|l|}{ Baseline WHO clinical stage } \\
\hline Mild WHO stage & 24 & 3.50 & 16 & 33 \\
\hline Advance stage & 20 & 1.40 & 15 & 24 \\
\hline \multicolumn{5}{|c|}{ Past OI before HARRT initiation } \\
\hline Yes & 17 & 0.56 & 12 & 23 \\
\hline No & 24 & 0.58 & 20 & 33 \\
\hline \multicolumn{5}{|l|}{ Baseline weight } \\
\hline$\geq 50 \mathrm{Kg}$ & 23 & 2.54 & 8 & 35 \\
\hline$<50 \mathrm{Kg}$ & 20 & 2.24 & 18 & 24 \\
\hline \multicolumn{5}{|l|}{ Baseline BMI } \\
\hline$<18.5$ & 19 & 2.34 & 12 & 24 \\
\hline$\geq 18.5$ & 24 & 1.75 & 18 & 35 \\
\hline \multicolumn{5}{|l|}{ Functional status } \\
\hline Working & 23 & 1.94 & 12 & 30 \\
\hline Ambulatory & 36 & 3.84 & 18 & 44 \\
\hline Bedridden & 18 & 1.49 & 12 & 24 \\
\hline \multicolumn{5}{|l|}{ Baseline CD4 Count } \\
\hline$\geq 200$ cells $/ \mathrm{mm}^{3}$ & 24 & 1.05 & 19 & 36 \\
\hline$<200$ cells $/ \mathrm{mm}^{3}$ & 18 & 1.55 & 14 & 23 \\
\hline \multicolumn{5}{|c|}{ Cotrimoxazole preventive therapy } \\
\hline Yes & 24 & 2.99 & 18 & 36 \\
\hline No & 18 & 0.49 & 14 & 21 \\
\hline
\end{tabular}

DOI: http://dx.doi.org/10.4314/ejhs.v29i2.4 
Table 2 continued...

\begin{tabular}{|c|c|c|c|c|}
\hline \multicolumn{5}{|c|}{ Isoniazid preventive therapy } \\
\hline Yes & 19 & 2.52 & 15 & 27 \\
\hline No & 21 & 1.62 & 17 & 30 \\
\hline \multicolumn{5}{|l|}{ Adherence level } \\
\hline Good & 24 & 2.01 & 19 & 43 \\
\hline Fair & 20 & 1.68 & 14 & 27 \\
\hline Poor & 18 & 0.39 & 12 & 21 \\
\hline \multicolumn{5}{|c|}{ Initial regimen substitution } \\
\hline Yes & 23 & 2.16 & 17 & 30 \\
\hline No & 20 & 1.7 & 14 & 24 \\
\hline \multicolumn{5}{|c|}{ First line regimen started } \\
\hline Nevirapine based & 24 & 3.03 & 17 & 39 \\
\hline Efavirenz based & 20 & 1.29 & 15 & 24 \\
\hline
\end{tabular}

Comparison of survival curves: The Log rank test showed that there were significant differences in survival times between the different categories of history of substance use $(p<0.001)$, time since HIV diagnosis $(p<0.001)$, duration on ART $(\mathrm{p}<0.002)$, under nutrition (low $\mathrm{BMI}<18 \mathrm{Kg} / \mathrm{m}^{2}$ ) at the start of ART $(p<0.001)$, opportunistic infection at the start of ART $(\mathrm{p}<0.002)$, low baseline CD4 count $<200$ cells $/ \mathrm{mm}^{3}(p<0.0004)$ and history of regimen substitution $(\mathrm{p}<0.001)$ (Figure 1 and 2).

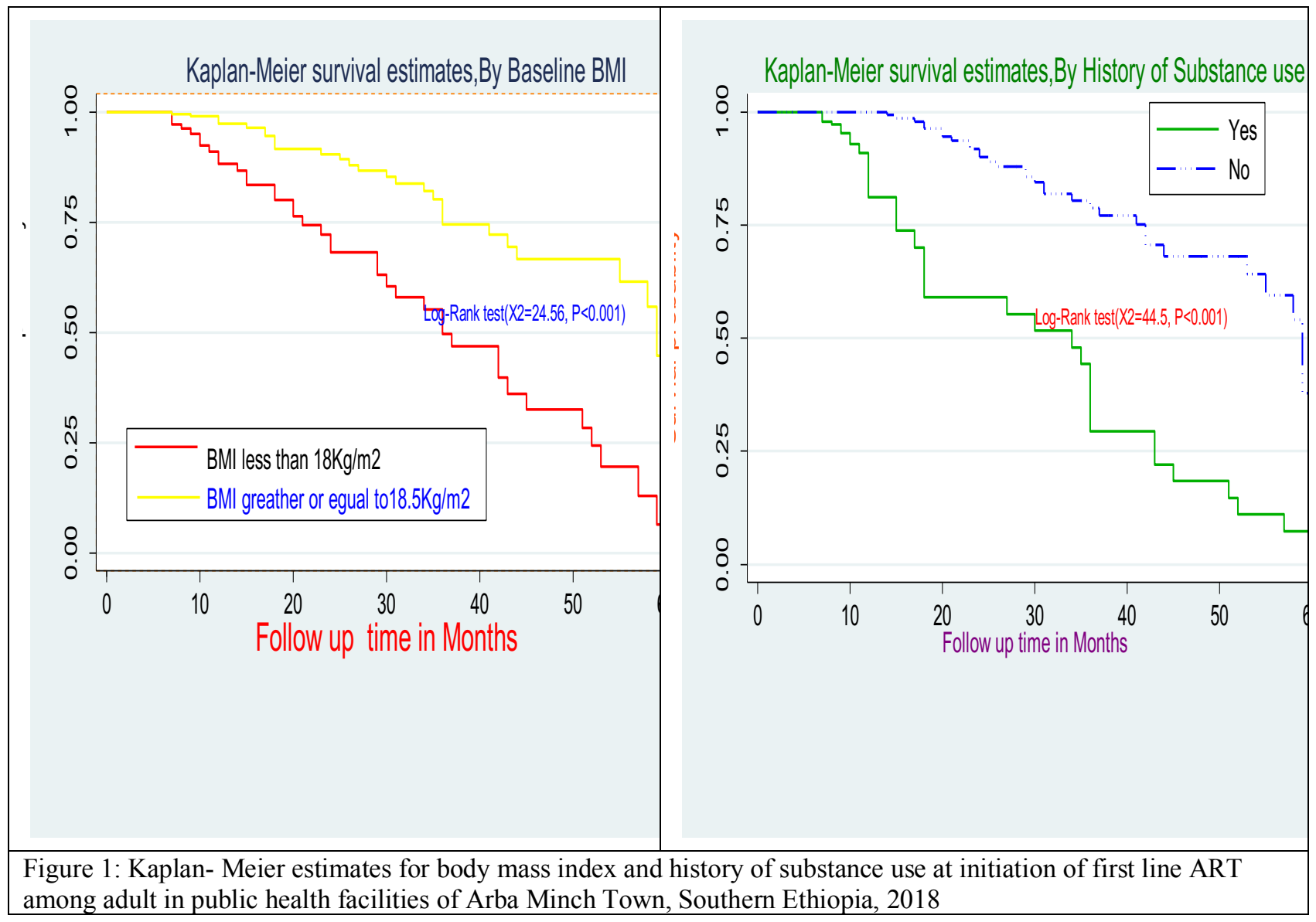

DOI: http://dx.doi.org/10.4314/ejhs.v29i2.4 


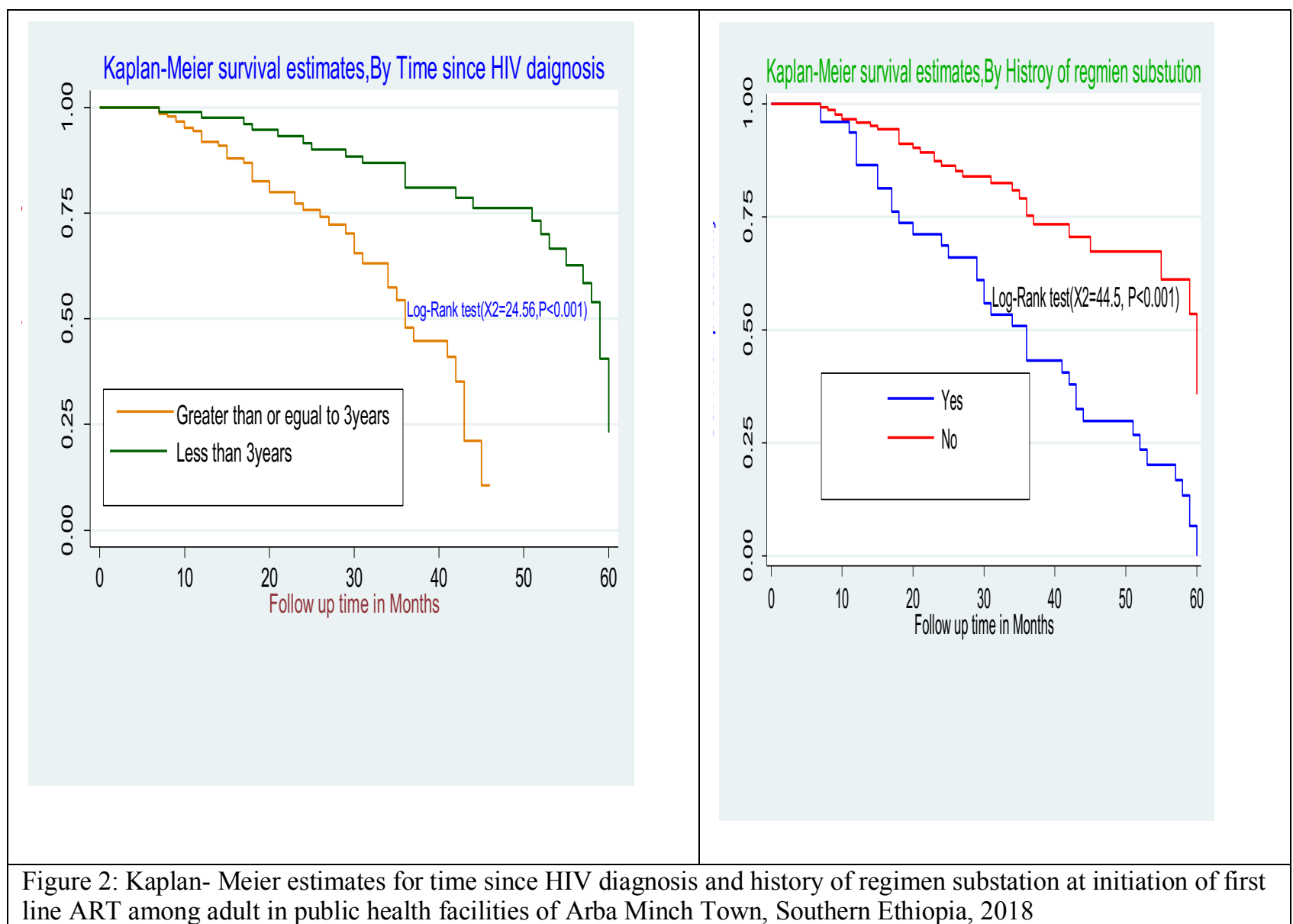

Predictors of time to first line antiretroviral treatment failure: In the bi-variable analysis of the covariates of sex, educational status, history of substance use, year since HIV diagnosis, duration on ART, disclosure status, baseline weight, under nutrition at baseline, low CD4 counts of $<200$ cells $/ \mathrm{mm}^{3}$ at baseline, advanced WHO staging at baseline, baseline functional status, history of opportunistic infection at initiation of ART, adherence to ART and initial regimen substitution were statistically significant at $25 \%$ level of significance; they were candidates for multi-variable analysis (Table 3 ).

During multi-variable Cox regression analysis, history of substance use, lack of disclosure status, time since HIV diagnosis, low CD4 counts, opportunistic infection, bedridden functional status, poor adherence to ART and under-nutrition were found to be independent predictors of time to first line antiretroviral therapy among adult HIV infected patients after they start ART (Table 3). 
Table 3: Bi-variable and multi-variable Cox proportional hazard analysis for predictors of time to first line antiretroviral treatment failure among adult people living with HIV in public health facilities of Arba Minch Town, Southern Ethiopia, 2018.

\begin{tabular}{|c|c|c|c|}
\hline Co-variates & CHR (95\% CI) & AHR (95\% CI) & p-values \\
\hline \multicolumn{4}{|l|}{ Sex } \\
\hline Male & $1.39(0.85,2.28)$ & $0.99(0.57,1.74)$ & 0.994 \\
\hline Female & 1 & & \\
\hline \multicolumn{4}{|l|}{ Educational status } \\
\hline No education & $0.67(0.36,1.23)^{*}$ & $1.26(0.31,5.05)$ & 0.747 \\
\hline Primary education & $1.61(1.02,2.54)^{*}$ & $1.41(0.4,4.99)$ & 0.59 \\
\hline Secondary education & $1.44(0.96,2.16)^{*}$ & $1.42(0.42,4.81)$ & 0.58 \\
\hline Tertiary education & 1 & & \\
\hline \multicolumn{4}{|c|}{ Duration on ART (months) } \\
\hline$<12$ & $1.33(1.03,17)$ & $0.94(0.52,1.68)$ & 0.824 \\
\hline$\geq 12$ & 1 & & \\
\hline \multicolumn{4}{|l|}{ Disclosure status } \\
\hline Disclosed & 1 & & \\
\hline Not disclosed & $2.62(1.49,4.62)^{*}$ & $1.98(1.03,3.79)$ & $0.04 * *$ \\
\hline \multicolumn{4}{|c|}{ History of Substance used } \\
\hline Yes & $1.76(1.05,2.95)^{*}$ & $2.94(1.62,5.32)$ & $0.001 * *$ \\
\hline No & 1 & & \\
\hline \multicolumn{4}{|c|}{ Time since HIV diagnosis (Years) } \\
\hline$\leq 3$ Years & $2.15(1.56,2.97)^{*}$ & $2.19(1.01,4.79)$ & $0.05 * *$ \\
\hline$>3$ Years & 1 & & \\
\hline \multicolumn{4}{|c|}{ Baseline WHO clinical stage } \\
\hline Stage I or II & 1 & & \\
\hline Stage III or IV & $1.45(0.89,2.34) *$ & $2.02(1.02,4.00)$ & $0.045^{* *}$ \\
\hline \multicolumn{4}{|l|}{ Baseline functional status } \\
\hline Working & 1 & & \\
\hline Ambulatory & $1.61(0.87,2.98)^{*}$ & $1.04(0.49,2.19)$ & 0.927 \\
\hline Bedridden & $4.31(2.49,7.44)^{*}$ & $2.71(1.33,5.51)$ & $0.006^{* *}$ \\
\hline \multicolumn{4}{|l|}{ History of OI at baseline } \\
\hline Yes & $1.72(1.06,2.78)$ & $2.37(1.23,4.19)$ & $0.009^{* *}$ \\
\hline No & 1 & & \\
\hline \multicolumn{4}{|l|}{ Baseline Weight (kg) } \\
\hline$\geq 50$ & $0.85(0.64,1.12)^{*}$ & $0.64(0.32,1.28)$ & 0.25 \\
\hline$<50$ & 1 & & \\
\hline \multicolumn{4}{|l|}{ Baseline BMI $\left(\mathrm{Kg} / \mathrm{m}^{2}\right)$} \\
\hline$<18.5$ & $3.11(1.92,5.04) *$ & $3.78(1.99,7.17)$ & $0.001 * *$ \\
\hline$\geq 18.5$ & 1 & & \\
\hline \multicolumn{4}{|l|}{ Baseline CD4 Count } \\
\hline$\geq 200$ cells $/ \mathrm{mm}^{3}$ & 1 & & \\
\hline$<200$ cells $/ \mathrm{mm}^{3}$ & $2.36(1.44,3.86)$ & $1.99(1.05,3.75)$ & $0.034 * *$ \\
\hline \multicolumn{4}{|l|}{ Adherence level } \\
\hline Good & 1 & & \\
\hline Fair & $2.02(1.09,3.73)^{*}$ & $1.26(0.62,2.56)$ & 0.52 \\
\hline Poor & $2.12(1.22,3.68)^{*}$ & $1.99(1.05,3.76)$ & $0.035^{* *}$ \\
\hline \multicolumn{4}{|c|}{ History of initial regimen substitution } \\
\hline Yes & $2.15(1.69,2.74)^{*}$ & $1.26(0.93,1.69)$ & 0.140 \\
\hline No & 1 & & \\
\hline
\end{tabular}

DOI: http://dx.doi.org/10.4314/ejhs.v29i2.4 


\section{DISCUSSION}

This study reveal that the overall median survival time was 21 months. This finding is in line with studies conducted in the University of Gondar Teaching Hospital, Northwest Ethiopia [17.5 months $(95 \% \mathrm{CI}=8-36)]$ and in Southern Ethiopia $(12,18)$. However, this finding is lower than the finding in private health facilities in Addis Ababa, Ethiopia [49 months (95\% CI $=48$ - 51)] and in Zewditu Memorial Hospital, Ethiopia [53.54 months $(95 \%$ CI $=40.54-$ 55.46)] $(21,22)$. These differences could be due to the difference in the diagnostic criteria for treatment failure, differences in follow-up periods and the type of first line regimen used.

In this study, opportunistic infection at initiation of ART was one of the predictors that had a significant effect on time to first line antiretroviral treatment failure. This finding was in line with studies conduct in Southeastern Ethiopia and Zewditu Memorial Hospital, central Ethiopia $(13,22)$. This may be explained by the occurrence of opportunistic infections during ART which has multiple effects including pill burden, drug-drug interaction and overlapping toxicities which influence adherence (23).

The result from this study revealed that the time since HIV diagnosis was an important determinant of treatment failure. Patients, who were alive since HIV diagnosis for a longer period, appeared to have low risk of treatment failure. This finding is consistent with a study done in Addis Ababa, Ethiopia, in which those who had been less than three years old since HIV diagnosis had 13.87 times more hazards towards treatment failure as compared to more than three years (21). This might be due to low adherence of patients at early stage to their drug as a result of lack of awareness, lack of adequate support and acceptance of people living with HIV.

Regarding disclosure status, patients who did not disclose their HIV status to their family members were more likely to have treatment failure than those who disclosed it $(\mathrm{AHR}=1.98$, $95 \% \mathrm{CI}=1.03$ to $3.79, \mathrm{P}=0.04$ ). This finding was in agreement with the findings of studies conducted in private health facilities in Addis Ababa and Zewditu Memorial Hospital, central Ethiopia $(21,22)$. This might be due to the fact that being disclosed their status might reduce anxiety and improve adherence to ART.

This study found that low baseline CD4 count below 200cells $/ \mathrm{mm}^{3}$ at the start of first line ART increased the risk of developing treatment failure by nearly 2 times as compared to a CD4 count $\geq 200$ cells $/ \mathrm{mm}^{3}$ (AHR $=1.99,95 \%$ CI $=1.05$ to $3.75, \quad \mathrm{P}=0.034$ ). Similarly, the studies conducted in the University of Gondar Teaching Hospital, Ethiopia and Chiang Mai University Hospital, Thailand, showed that lower baseline CD4 cell count was one of the main predictors of first line ART treatment failure $(12,17)$. This might be due to the fact that patients with low baseline CD4 cell count have lesser immunity that might favor the probability of developing first line ART treatment failure.

The finding of our study on baseline functional status supports the findings in Debre Markos, Bale Zone and Addis Ababa Hospitals, Ethiopia (9, 16, 21). Those patients with bedridden baseline functional status had 2.71 times higher hazards when compared to working functional status $(\mathrm{AHR}=2.7195 \% \mathrm{CI}=1.33$ to $5.51, \mathrm{P}=0.006$ ). This could be due to the fact that patients became bedridden as a result of infectious diseases when their CD4 cell counts were low.

Our findings showed that individuals who began ART regimen with low baseline undernutrition (BMI $<18 \mathrm{Kg} / \mathrm{m}^{2}$ ) had 3.78 times (AHR=3.78, 95\% CI=1.99 to $7.17, \mathrm{P}=0.001)$ and those patients who were in the advanced WHO clinical stages III \& IV haa 2.02 times more hazards towards treatment failure when compared to those patients who were at WHO stage I or II $(\mathrm{AHR}=2.02,95 \% \mathrm{CI}=1.02$ to $4.00, \mathrm{P}=0.045)$, a greater risk of time to first line antiretroviral treatment failure. These results are supported by previous studies in Ethiopia and Mozambique $(12,14,18,21)$.

Finding of this study found that poor drug adherence was one of the predictors that had a significant effect on time to first line

DOI: http://dx.doi.org/10.4314/ejhs.v29i2.4 
antiretroviral treatment failure. This finding is consistent with the studies done in Kenya, Gondar, Bale and Thailand $(10,12,16,17)$. This might be due to the fact that HIV care providers were unable to assess adherence accurately, although standardized adherence assessment may be even more useful.

This study also found that high risk behaviors like substance use at initiation of ART had 2.94 times higher probability of ART treatment failure compared to those patients without history of substance use $(\mathrm{AHR}=2.94$, $95 \% \mathrm{CI}=1.62$ to $5.32, \mathrm{P}=0.001$ ). This finding was in line with a study done in an urban HIV/AIDS clinic in Addis Ababa, Ethiopia (7). This might be due to the fact that a person who has history of substance use has poor adherence to ART regimens, which in turn may lead to reduced CD4 count.

In conclusion, the overall median survival time was 21 months. Lack of disclosed HIV status to family members, history of opportunistic infection at initiation of ART, high risk behaviors like substance use, low baseline CD4 count of below 200cells $/ \mathrm{mm}^{3}$, low baseline undernutrition of BMI $<18 \mathrm{Kg} / \mathrm{m}^{2}$, advanced WHO clinical staging, bedridden baseline functional status and poor drug adherence were independent predictors of time to first line treatment failure. Therefore, preventive information and counseling that focus on high risk behaviors like history of substance use and lack of disclosure of their HIV status to their family members should be routinely provided to all adult living with HIV.

The strengths of this study are the use of standard measurements and the inclusion of the most important predictors of first line ART treatment failure. Since this study was based on secondary data and excluded patients records with incomplete information, survival time might be underestimated.

\section{ACKNOWLEDGMENTS}

We would like to thank the administrators of Arba Minch General Hospital and Health Center, and the health professionals and data collectors who contributed to this work.

\section{REFERENCES}

1. Assefa Y, Gilks CF, Lynen L, Williams O, Hill PS, Tolera $\mathrm{T}$, Malvia $\mathrm{A}$, et al. Performance of the Antiretroviral Treatment Program in Ethiopia, 2005-2015: strengths and weaknesses toward ending AIDS. International Journal of Infectious Diseases. 2017;60:70-6.

2. World Health Organization (WHO). Global Health Sector Strategy on HIV 2016-2021. Geneva, Switzerland. 2016. https://apps.who.int/iris/bitstream/handle/106 65/246178/WHO-HIV-2016.05eng.pdf?sequence $=1$

3. Joint United Nations Programme on HIV/AIDS (UNAIDS). Ending AIDS: Progress towards the 90-90-90 targets. Global AIDS Update. 2017. http://www.unaids.org/sites/default/files/medi a_asset/Global_AIDS_update_2017_en.pdf

4. The Ethiopian Public Health Institute, HIV Related Estimates and Projections for Ethiopia. The Ethiopian Public Health Institute, Ethiopia, March 2017. https://www.ephi.gov.et/images/pictures/dow nload2009/HIV_estimation_and_projection_f or_Ethiopia_2017.pdf

5. Country/Regional Operational Plan (COP/ROP). Strategic Direction Summary, Ethiopia. April 21, 2017. https://www.pepfar.gov/documents/organizati on/272012.pdf

6. Kwobah CM, Mwangi AW, Koech JK, Simiyu GN, Siika AM. Factors associated with first-line antiretroviral therapy failure amongst HIV-infected African patients: a case-control study. World Journal of AIDS. 2012 Dec 10;2(4):271-8.

7. Niemeyer K, King A, Mengistu S, Hennig N. Predictors for antiretroviral therapy (ART) failure in an urban HIV/AIDS clinic in Addis Ababa, Ethiopia. The Lancet Global Health. 2016 Apr 1;4:S6.

8. Rajasekaran $\mathrm{S}$, Jeyaseelan L, Vijila S, Gomathi C, Raja K. Predictors of failure of first-line antiretroviral therapy in HIVinfected adults: Indian experience. Aids. 2007 Jul 1;21:S47-53. 
9. Yayehirad AM, Mamo WT, Gizachew AT, Tadesse AA. Rate of immunological failure and its predictors among patients on highly active antiretroviral therapy at Debremarkos hospital, Northwest Ethiopia: a retrospective follow up study. Journal of AIDS and Clinical Research. 2013;4(5): 211.

10. Hassan AS, Nabwera HM, Mwaringa SM, Obonyo CA, Sanders EJ, de Wit TF, et al. $\mathrm{HIV}-1$ virologic failure and acquired drug resistance among first-line antiretroviral experienced adults at a rural HIV clinic in coastal Kenya: a cross-sectional study. AIDS research and therapy. 2014 Dec;11(1):9.

11. Fox MP, Shearer K, Maskew M, Macleod W, Majuba P, Macphail $\mathrm{P}$, et al. Treatment outcomes after seven years of public-sector HIV treatment at the Themba Lethu clinic in Johannesburg, South Africa. AIDS. 2012 Sep 10;26(14):1823.

12. Ayalew MB, Kumilachew D, Belay A, Getu $\mathrm{S}$, Teju D, Endale $\mathrm{D}$, et al. First-line antiretroviral treatment failure and associated factors in HIV patients at the University of Gondar Teaching Hospital, Gondar, Northwest Ethiopia. HIV/AIDS. 2016;8:141.

13. Setegn T, Takele A, Gizaw T, Nigatu D, Haile D. Predictors of mortality among adult antiretroviral therapy users in southeastern Ethiopia: retrospective cohort study. AIDS research and treatment. 2015; http://dx.doi.org/10.1155/2015/148769.

14. Palladino C, Briz V, Bellón JM, Bartolo I, Carvalho P, Camacho R, et al. Predictors of attrition and immunological failure in HIV-1 patients on highly active antiretroviral therapy from different healthcare settings in Mozambique. PLoS One. 2013 Dec 20;8(12): e82718.

15. Kapesa A, Magesa D, William A, Kaswija J, Seni J, Makwaya C. Determinants of immunological failure among clients on the first line treatment with highly active antiretroviral drugs in Dar es Salaam, Tanzania. Asian Pacific Journal of Tropical Biomedicine. 2014;4:S620-4.
16. Haile D, Takele A, Gashaw K, Demelash H, Nigatu D. Predictors of Treatment Failure among Adult Antiretroviral Treatment (ART) Clients in Bale Zone Hospitals, South Eastern Ethiopia. PloS one. 2016 Oct 7;11(10): e0164299.

17. Khienprasit N, Chaiwarith R, Sirisanthana T, Supparatpinyo K. Incidence and risk factors of antiretroviral treatment failure in treatment-naïve HIV-infected patients at Chiang Mai University Hospital, Thailand. AIDS research and therapy. 2011 Dec;8(1):42.

18. Yirdaw KD, Hattingh S. Prevalence and predictors of immunological failure among HIV patients on HAART in Southern Ethiopia. PloS one. 2015 May 11;10(5): e0125826.

19. Babo YD, Alemie GA, Fentaye FW. Predictors of first-line antiretroviral therapy failure amongst HIV-infected adult clients at Woldia Hospital, Northeast Ethiopia. PloS one. 2017 Nov 2;12(11): e0187694.

20. Ministry of Health (MOH). (2017). National guidelines for comprehensive HIV prevention, care and treatment. Addis Ababa: Ministry of Health. February 2017. https://aidsfree.usaid.gov/sites/default/files/re sources/ethiopia_art_guidelines_2017.pdf

21. Yimer YT, Yalew AW. Magnitude and predictors of anti-retroviral treatment (ART) failure in private health facilities in Addis Ababa, Ethiopia. PLoS One. 2015 May 6;10(5): e0126026.

22. Sisay C, Bekele A, Sisay A, Mekonen H, Terfa K. Incidence and Predictors of AntiRetroviral Treatment (ART) Failure among Adults Receiving HIV Care at Zewditu Memorial Hospital, Addis Ababa, Ethiopia. $J$ AIDS Clin Res. 2017;8(12):2.

23. Rajian M, Gill PS, Chaudhary U. Effect of Tuberculosis Co infection on Virological Failure in HIV Patients on First Line of Highly Active Antiretroviral Therapy. IntJCurrMicrobiolAppSci. 2017;6(1):78-81.

DOI: http://dx.doi.org/10.4314/ejhs.v29i2.4 